\title{
Birinci Trimesterde Abortus İmminens Tanısı Konulan Gebelerin Perinatal Sonuçlarının Değerlendirilmesi
}

\section{Evaluation of Perinatal Results of Pregnant Women Diagnosed with Abortus Imminence in the First Trimester}

\author{
${ }^{1}$ İsa Şükrü ÖZ \\ ${ }^{1}$ Afyon Özel Fuar Hastanesi, Afyon, Türkiye \\ İsa Şükrü Öz : https://orcid.org/0000-0001-8849-2705
}

\begin{abstract}
ÖZ
Amaç: Birinci trimesterde abortus imminens tanısı alan gebelerin prognozlarını takip ederek perinatal sonuçlarının değerlendirilmesidir.

Materyal ve Metot: Çalışmaya Ocak 2019 ile Temmuz 2019 arası zaman diliminde hastanemiz kadın hastalıkları ve doğum kliniğine başvuran abortus imminens tanısı alan 100 hasta çalışma grubunu, diğer 100 kişilik grup kontrol grubunu oluşturdu. Çalışmaya katılan gebelerin yaş, parite, gravida sayıları, demografik özellikleri, prognozları takip edilerek oluşan fetal ve maternal perinatal sonuçları kayıt altına alındı. Grupların kıyaslanması normal dağılan numerik verilerde Student t testi, normal dağılmayan numerik verilerde Mann Whitney testi, kategorik verilerde ki-kare testi ile yapıldı.

Bulgular: Gebeler doğum parametreleri açısından incelendiğinde doğum şekli ve maternal doğum komplikasyonları açısından gruplar arasında fark olmadığı görüldü $(\mathrm{p}=1,000$ ve $\mathrm{p}=0,276)$. Prematür membran rüptürü (PROM) görülme sıklığ1 abortus imminens tanısı alan grupta daha fazladır ve gruplar arasındaki fark istatistiksel olarak anlamlıdır $(\mathrm{p}<0,001)$. Düşük ve kürtaj öyküsü, alkol kullanımı, ek hastalık varlığ $\breve{1}_{\text {, sosyal güvence varlı } \breve{g}}$ açısından da gruplar arasında fark gözlenmedi $(\mathrm{p}>0,05)$.

Sonuç: Abortus imminens vakaları kötü obstetrik sonuçlarla ilişkilidir. Abortus imminens vakalarının prognozunda prematür membram rüptürü görülme sıklığ artmıştır.
\end{abstract}

Anahtar Kelimeler: Abortus imminens, perinatal sonuçlar, prematür membran rüptürü

\begin{abstract}
Objective: The aim of this study is to evaluate the perinatal outcomes of pregnant women diagnosed with abortus imminens in the first trimester.

Materials and Methods: The study group consisted of 100 patients diagnosed with abortion imminens and the control group of 100 patients who applied to our hospital's gynecology and obstetrics clinic between January 2019 and July 2019. Fetal and maternal perinatal outcomes were recorded by monitoring the age, parity, number of gravida, demographic characteristics and prognosis of pregnant women. The comparison of the groups was done by Student $t$ test in normal distributed data, Mann Whitney test in normal non-distributed numerical data, and chisquare test in categorical data. $\mathrm{P}<0.05$ was considered statistically significant.
\end{abstract}

Results: When the pregnant women were examined in terms of birth parameters, there was no difference between groups in terms of delivery type and maternal birth complications $(p=1,000$ and $p=0.276)$. However, the incidence of premature rupture of membranes (PROM) were higher in the group diagnosed with abortion and the difference between the groups was statistically significant $(p<0.001)$. There was no difference between the groups in terms of abortion and abortion history, alcohol use, presence of comorbidity, and social security ( $p>0.05)$.

Conclusion: Abortus imminens cases are associated with poor obstetric outcomes. The incidence of premature rupture of membranes have increased in the prognosis of abortus imminens cases.

Keywords: Abortus imminens, perinatal outcomes, premature rupture of membranes

\footnotetext{
Sorumlu Yazar / Corresponding Author: İsa Şükrü Öz,

Afyon Özel Fuar Hastanesi, Afyon, Türkiye

Tel: +90 - 5069588588

E-mail: isasukruoz@gmail.com
}

Yayın Bilgisi / Article Info:

Gönderi Tarihi/ Received: 30/11/2019

Kabul Tarihi/ Accepted: 30/11/2020

Online Yayın Tarihi/ Published: 05/03/2021

Atıf / Cited: Öz İŞ. Birinci Trimesterde Abortus İmminens Tanısı Konulan Gebelerin Perinatal Sonuçlarının Değerlendirilmesi. Online Türk Sağlık Bilimleri Dergisi 2021;6(1):129-134. doi: 10.26453/otjhs.653484 


\section{GÍRIŞ}

Her anne adayı gebeliğini öğrendikten sonra gebeliğinin sorunsuz olarak tamamlanmasını ister; fakat gebeliklerin bir kısmı abortus dediğimiz gebelik kayıpları ile sonuçlanır. Gebeliğin ilk 20 haftasından önce en s1k görülen gebelik komplikasyonu spontan abortuslardır. ${ }^{1} \mathrm{Bu}$ spontan abortusların büyük bölümünde fetüs canlılık göstermez ve kanama ile embriyonel kayıp gerçekleşir. Kayıpların birçoğunda bu durum fark edilmez. Abortus imminens gebeliğin 20. haftasından öncesinde görülen, pelvik ağrı ve kanamanın eşik edebileceği, düşük tehlikesi durumunun orta çıkmasıdır. ${ }^{2}$ Abortus imminens durumunda serviks kapalıdır, servikal açıklık gözlenmez ve vajinal tuşede serviks hareketleri normal olarak izlenir. Ultrasonografik olarak yalnız gebelik kesesi izlenebileceği gibi fetal kalp atımları da görülebilir. Ayrıca gebelik kesesi etrafında çeşitli boyutlarda kanama alanları görülebilir. Gebelerde abortus imminens durumunun görülme oranı yaklaşı $\% 20$ dir. Servikal ve vajinal enfeksiyonlarda abortus immines durumuna sebep olabilirler. Bunlardan düşük tehdidi açısından en önemlisi bakteriyel vaginosistir. Bakteriyel vaginosis enfeksiyonu düşük riskini artırır., ${ }^{2,3}$ Abortus imminens ayırıcı tanısında servikal polip, dış gebelik, vajinal ve servikal enfeksiyonlar göz önünde bulundurulmalıdır., ${ }^{2,4}$ Klinik gözlemlerimiz eşiğinde abortus imminensli bir gebenin gebeliğinin nasıl sonuçlanacağı belirsizdir. Abortus imminensli hastaların gebeliklerinin devamında ne tür komplikasyonların olabileceği konusu öngörülememektedir.

Biz bu çalışmamızda abortus imminens tanısı konulan gebelerimizin prognozların belirlemek amacıyla, abortus imminens tanısı alan gebelerin perinatal sonuçlarını inceledik.

\section{MATERYAL VE METOT}

Çalışma Helsinki Deklerasyonu Prensipleri'ne uygun olarak yapılmıştır. Zonguldak Bülent Ecevit Üniversitesi İnsan Araştırmaları Etik Kurulu'ndan onay ve çalışmaya katılmış insanlardan "Bilgilendirilmiş Olur" alınmıştır (Tarih: 08/05/2019, karar no:2019-76-08/05).

Çalışmamız Ocak 2019 ile Temmuz 2019 tarihleri arasında hastanemiz kadın hastalıkları doğum kliniğine başvuran, gebelik yaşları 5 hafta ile 14 hafta arasında değişen toplam 200 gebe olarak çalışmaya alınmıştır. $\mathrm{Bu} 200$ hastadan 100 adeti abortus imminens tanısı alan çalışma grubu, diğer 100 kişilik grup ise kontrol grubunu oluşturmuştur. Kontrol grubu aynı süre zarfında hastanemize rutin kontroller dışında herhangi bir pelvik ağrı veya kanama şikâyeti ile başvurmayan gebelerden seçilmiştir. Çalışma prospektif olarak yapılmıştır. Abortus imminens tanısı vajinal kanamaya sebep olabilecek diğer nedenler dışlandıktan sonra, vajinal kanaması ve pelvik ağrısı olan, servikal dilatasyonu olmayan, ultrasonografik olarak gebelik kesesi veya fetal kalp atımı görülen gebelere konmuştur. Ultrasonografik olarak gebenin gebelik yaşına göre vajinal ve abdominal ultrason probları kullanılmıştır. Ultrasonografik olarak muayenede gebelik kesesi varlığı, gebelik kesesinin sınırlarının düzgün olup olmadığı, fetal kalp atım varlığı, subkoryonik hematom varlığı kayıt altına alındı. Vaijnal kanama ve pelvik ağrıya sebep olabilecek sistemik hastalığı ve ilaç kullanımı olanlar, tekrarlayan gebelik kayıpları olanlar ve daha önceki gebeliklerinde servikal yetmezliği olanlar çalışmaya dâhil edilmedi. Vajinal kanama ve pelvik ağrı ile hastanemize mükerrer başvurular çalışmaya dahil edilmedi. $\mathrm{Bu}$ hastaların abortus imminens nedeni ile ilk başvuruları esas alındı. Her iki grup gebelerin yaş, gravida, parite, düşük, kürtaj öyküleri ve demografik özelliklerinin yanı sıra prognozu belirlemek amacıyla ilerleyen gebeliklerinin düşükle sonuçlanıp sonuçlanmadığı, doğum haftaları, doğumlarında komplikasyon olup olmadığı, doğum şekilleri, sigara ve alkol kullanımları, alerji öyküleri kayıt altına alındı. Doğum komplikasyonu olarak anne de dekolman plasenta, plasenta previa, doğumda plasentanın elle çıkarılması, preeklampsi durumlarına bakıldı. Fetus açısından ise prematür membran rüptürü (PROM), preterm doğum, intrauterin gelişme geriliği (IUGR), düşük doğum ağırlığı, düşük apgar skoru, doğumda mekonyum varlığı, oligohidroamnios varlığg, polihidroamnios varlığı, fetal kayıp, doğum sonrası yenidoğan yoğun bakım ihtiyacı durumlarına bakıldi.

Istatistiksel Analiz: Verilerin istatistiksel analizi SPSS 21.0 (IBM Corp. Released 2012. IBM SPSS Statistics for Windows, Version 21.0. Armonk, NY: IBM Corp.) ile yapıldı. Verilerin normal dağılıma uygunluğu grafiksel olarak ve Shapiro-Wilk testi ile incelendi. Verilerin gösteriminde normal dağılan numerik verilerde ortalama ve standart sapma, normal dağılmayan numerik verilerde ortanca ve minimum-maksimum, kategorik verilerde sayı ve yüzde kullanıldı. Grupların kıyaslanması normal dağılan numerik verilerde Student $\mathrm{t}$ testi, normal dağılmayan numerik verilerde Mann Whitney testi, kategorik 
verilerde ki-kare testi ile yapıld1. $\mathrm{P}<0,05$ istatistiksel olarak anlamlı olarak kabul edildi.

\section{BULGULAR}

Çalışmaya toplam 200 vaka alındı. 100 hasta abortus imminens grubunu, 100 hasta ise kontrol grubunu oluşturmaktaydı. Ortalama yaş $28,7 \pm 3,8$, ortanca doğum haftası 39 (34-41) hafta idi. $153(\% 76,5)$ hasta normal doğum yaparken, $47(\% 23,5)$ hasta sezaryen ile doğum yaptı. Gruplar birbiriyle kıyaslandığında yaş, gravida, parite ve doğum haftaları açısından fark tespit edilmedi ( $\mathrm{p}>0,05)$ (Tablo 1) .

Hastalar doğum parametreleri açısından incelendiğinde doğum şekli ve maternal doğum komplikasyonları açısından gruplar arasında fark olmadığı görüldü ( $p=1,000$ ve $p=0,276)$. PPROM'lu hastalar incelendiğinde 18 (\%72) hastanın çalışma grubunda, 7 (\%28) hastanın kontrol grubunda olduğu görülmüştür. PROM görülme sıklığı abortus imminensli grupta daha fazladır ve gruplar arasındaki fark istatistiksel olarak anlamlıdır $(\mathrm{p}<0,001)$. Düşük, kürtaj öyküsü, alkol kullanımı, ek hastalık varlığı, sosyal güvence ve erken doğum görülme açısından da gruplar arasında fark gözlenmedi $(\mathrm{p}>0,05)$. Gruplarda alerji öyküsü olan hastaya rastlanmadı (Tablo 2). Sigara içen hastalar incelendiğinde $34(\% 79,1)$ hastanın abortus imminens grubunda, $9(\% 20,9)$ hastanın ise kontrol grubunda olduğu görüldü. Aradaki farkın istatistiksel olarak anlamlı olduğu tespit edildi $(\mathrm{p}<0,001)$ (Tablo 2).

Ortaokul ve lise mezunu olanlarda abortus imminens vakalarının daha sık olduğu görüldü. İlkokul ve ön lisans mezunu olanlarda ise abortus imminens vakalarının daha az olduğu tespit edildi $(\mathrm{p}=0,021)$ (Tablo 2).

\section{TARTIŞMA VE SONUÇ}

Fetal kalp atımının ultrasonografik olarak görülmesinin ardından gebelik kaybının görülme ihtimali \% 3,7'dir. ${ }^{1}$ Abortus imminens vakalarında fetal kalp atımı görüldükten sonra gebelik kaybı görülme ihtimali ise yaklaşık \%20'dir. ${ }^{5}$ Wilcox ve ark. ${ }^{6}$ ilk trimesterde yaşanan gebelik kayıplarının büyük bir çoğunluğunun kromozom anomalilerinden kaynaklandığını ortaya koymuşlardır. Basama ve ark. ${ }^{7}$ gebelerin yaşlarının ilerlemesi ile erken gebelik haftalarında vajinal kanamaların daha sık görüleceğini ifade etmişlerdir. Ayrıca abortus imminens görülme sıklığının gebenin yaşının artmasıyla artacağını ortaya koymuşlardır. Bizim çalışmamızda ise abortus imminens görülme sıklığının yaşla bir ilgisinin olmadığı sonucuna varılmıştır ( $\underline{\text { Tablo1 }})$. Bu konuda bizim çalışmamızı destekleyen yayınlar literatürde mevcuttur. ${ }^{8}$ Obed ve ark. ${ }^{9}$ abortus imminens tanıs1 alan gebelerin gebeliklerinin devamında plasenta previa görülme olasılığının arttığını belirtmişlerdir. Fakat Davari-Tanha ve ark. ${ }^{10}$ bu görüşü desteklememiş abortus imminens ile plasenta previa arasında bir bağlantı olmadığını ifade etmişlerdir. Bizim çalışmamızda da çalışma grubu ile kontrol grubu arasında plasenta previa gelişimi ile ilgili anlamlı bir fark bulunamadi. Johns ve ark. ${ }^{11}$ abortus imminens tanısı alan gebelerde plasenta dekolmanı görülme olasılığının arttığını belirtmişlerdir. Fakat Wijesiriwardana ve ark. ${ }^{1}$ abortus imminens tanıs alan gebelerde dekolman plasenta görülme sıklığının artmadığını belirtmişlerdir. Bizim çalışmamızda da çalışma ve kontrol grubu arasında dekolman plasenta açısından anlamlı fark bulunamadı. Yapılan çalışmalar göstermiştir ki abortus imminens tanısı alan gebelerin prognozunda erken doğum görülme oranı artar. $^{11,12}$ Bizim çalışmamızda iki grup arasında böyle bir oran artışı izlenmemiştir. Ayrıca preterm prematür membran rüptürünün (PPROM) abortus imminens tanısı alan gebelerde daha sık görüldüğünü belirten çalışmalar mevcuttur. ${ }^{8,11}$ Fakat bu çalışmalarda PPROM görülme sıklığının altta yatabilecek başka bir risk faktörüne bağlı olabileceğinin de altı çizilmiştir. Bizim çalışmamızda ise çalışma grubunda PROM görülme sıklığı artmıştır. Abortus imminens tanılı gebelerin bebeklerinin doğduktan sonra düşük apgar skorlu olup olmadıkları ve yeni doğan yoğun bakıma ihtiyaç duyup duymadıkları ile ilgili yapılan çalışmalara bakıldığında abortus imminens tanısı almış gebelerin bebeklerinin düşük apgar skoru ile doğduklarını ve yeni doğan yoğun bakıma ihtiyaç duyduklarının belirten çalışmalar vardır. ${ }^{13,14}$ Fakat bizim çalışmamızda düşük apgar skoru ve yeni doğan yoğun bakım ihtiyacı açısından iki grup arasında fark izlenmemiştir. Konuya abortus imminens tanısı alan gebelerde intra uterin gelişim geriliği gelişimi açısından bakıldığında abortus imminens tanısı alan gebelerde IGUR görülme sıklığ1 artar diyen yayın olduğu gibi, ${ }^{12}$ IUGR görülme sıklığı artmaz diyen yayın da vardır. ${ }^{14}$ Burada başka önemli bir nokta ise IUGR görülme sıklığı artar diyen yayında IUGR yanında konjenital anomali görülme sıklığının da arttığının da belirtilmiş olmasıdır. Bizim çalışmamızda IUGR gelişimi açısından iki grup arasında fark bulunamamıştır. Prognoz açısından çalışmalara bakıldığında abortus imminens tanısı alan gebelerde perinatal mortatilitenin arttığını belirten yayınlar mevcuttur; ${ }^{10,12}$ fakat tam tersini savunan yayınlarda mevcuttur. ${ }^{13}$ Doğum sırasında 
mekonyum varlığ 1 , polihidroamnios veya oligohidroamnios gelişimi ile abortus imminens tanısı alan gebeler arasındaki ilişki açısından literatürde geniş çaplı bir çalışma bulunamadı. Bizim çalışmamızda ise bu parametreler açısından iki grup arasında önemli bir fark izlenmedi. Bizim çalışmamızda ilaveten sigara içen hastalarda abortus imminens vakalarının daha sık görüldüğü ortaya konulmuştur. Eğitim düzeyi ile ilişkiler açısından bakıldığında bizim çalışmamızda abortus imminens tanısı alan vakalar daha çok ortaokul ve lise mezunlarında görülmekle birlikte ilkokul ve ön lisans mezunlarında abortus imminens vakaları daha az görülmektedir. Evrenos ve ark. ${ }^{15}$ yaptıkları çalışmada abortus imminens tanısı alan hastaların prognozunda kötü perinatal sonuçlar olabileceğini hatta altta yatan başka bir risk faktörü varsa erken gebelik haftalarında da kötü sonuçlar olabileceğini belirtmişlerdir Sonuç olarak; Abortus imminens vakaları kötü obstetrik sonuçlarla ilişkilidir. Abortus imminens vakalarının prognozunda PROM görülme sıklıkları artmıştır. Klinik uygulamada abortus imminensli vakaların takibinde, gebeler ilerleyen dönemlerdeki kötü obstetrik sonuçlar ile ilgili olarak bilgilendirilmelidir. Klinisyen kötü obstetrik sonuçlar açısından gebeleri yakından takip etmelidir.

Etik Komite Onayı: Çalışmamız Bülent Ecevit Üniversitesi, Etik Kurulu tarafindan onayland 1 (Tarih:08/05/2019, karar no:2019-76-08/05).

Çıkar Çatışması: Yazar çıkar çatışması bildirmemektedir.

Yazar Katkıları: Fikir İŞÖ; Denetleme İŞÖ; Malzemeler İ̧Ö; Veri toplanması ve işlemesi İ̧Ö; Analiz ve yorum İŞÖ; Yazıyı yazan İ̧̧Ö.

Hakem değerlendirmesi: D1ş bağımsız.

Teşekkür: Çalışmaya katılan tüm gebelere teşekkür ederiz.

\section{KAYNAKLAR}

1. Wijesiriwardana A, Bhattacharya S, Shetty A, Smith N. Obstetric outcome in women with threatened miscarriage in the first trimester. Obstet Gynecol. 2006;107:557-562.

2. Sotiriadis A, Papatheodorou S, Makrydimas G. Threatened miscarriage evaluation and management. BMJ. 2004;329:152-155.

3. Johns J, Jauniaux E. Threatened miscarriage as a predictor of obstetric. Obstet Gynecol. 2006; 107:845-850.

4. Haas DM, Hathaway TJ, Ramsey PS. Progestogen for preventing miscarriage (Review). Coch- rane Database Syst Rev. 2013;10:CD003511. doi: 10.1002/14651858.CD003511.pub3

5. Wang JX, Norman RJ, Wilcox AJ. Incidence of spontaneous abortion among pregnancies produced by assisted reproductive technology. Hum Reprod. 2004;19:272-277. doi:10.1093/humrep/ deh078

6. Wilcox AJ, Weiberg CR, O'Connor JF, ve ark. Incidence of early loss of pregnancy. $\mathrm{N}$ Engl $\mathrm{J}$ Med. 1988;319-189. doi:10.1056/ nejm198807283190401

7. Basama FM, Crosfill F. The outcome of pregnancies in 182 women with threatened miscarriage. Arch Gynecol Obstet. 2004;270:86-90. doi: https://doi.org/10.1007/s00404-003-0475-z

8. Dadkhah F, Kashanian M, Eliasi G. A comparison between the pregnancy outcome in women with or without threatened abortion. Early $\mathrm{Hu}$ man Dev. 2010;86:193-196.

9. Obed JY, Adewole IF. Antepartum hemorrhage: the influence of first trimester uterine bleeding. West Afr J Med. 1997;16:24-26.

10. Davari-Tanha F, Shariat M, Kaveh M, Ebrahimi M, Jalalvand S. Threatened abortion: A risk factor for poor pregnancy outcome. Acta Med İran. 2008;46:314-320.

11.Johns J, Hyett J, Jauniaux E. Obstetric outcome after threatened miscarriage with and without a hematoma on ultrasound. Obstet Gynecol. 2003;102:483-487.

12. Mulik V, Bethel J, Bhal K. A retrospective populationbased study of primigravid women on the potential effect of threatened miscarriage on obstetric outcome. J Obstet Gynaecol. 2004;24:249-253.

13. Sipila P, Hartikainen Sorri AL, Oja H, Von WL. Perinatal outcome of pregnancies complicated by vaginal bleeding. Br J Obtstet Gynaecol. 1992;99:959-963.

14. Tongsong T, Srisomboon J, Wanapirak C, Sirichotiyakul S, Pongsatha S, Polsrisuthikul T. Pregnancy outcome of threatened abortion with demonstrable fetal cardiac activity: A cohort study. J Obstet Gynaecol. 1995;21:331-335. doi:10.1111/j.1447-0756.1995.tb01019.x

15. Evrenos AN, Gungor AN, Gulerman C, Cosar E. Obstetric outcomes of patients with abortus imminens in the first trimester. Arch Gynaecol Obstet. 2014;289(3):499-504. doi:10.1007/s00404-013-2979-5 
Tablo 1. Hastalara ait demografik verilerin gruplara göre dağılımı.

\begin{tabular}{|l|l|l|l|}
\hline & $\begin{array}{l}\text { İmminens } \\
(\mathbf{n = 1 0 0})\end{array}$ & $\begin{array}{l}\text { Kontrol } \\
\mathbf{( n = 1 0 0 )}\end{array}$ & $\mathbf{p}$ \\
\hline Yaş & $28,3 \pm 3,9$ & $29,1 \pm 3,7$ & 0,145 \\
\hline Gravida & $2(1-4)$ & $2(1-3)$ & 0,902 \\
\hline Parite & $1(0-2)$ & $1(0-2)$ & 0,518 \\
\hline Doğum Haftası & $39(34-41)$ & $39(34-41)$ & 0,267 \\
\hline
\end{tabular}

Veriler ortalama \pm standart sapma ve ortanca (minimum-maksimum) olarak verilmiştir. $\mathrm{P}<0,05$ istatistiksel olarak anlamlı fark mevcut. 
Tablo 2. Gruplara ait gebelik, doğum ve sosyal parametrelerin dağılımı.

\begin{tabular}{|c|c|c|c|c|c|c|}
\hline & & \multicolumn{4}{|c|}{ Grup } & \multirow[b]{3}{*}{$\mathrm{p}$} \\
\hline & & \multicolumn{2}{|c|}{ Kontrol ( $n=100)$} & \multicolumn{2}{|c|}{$\begin{array}{l}\text { İmminens } \\
(\mathrm{n}=100)\end{array}$} & \\
\hline & & $\mathrm{n}$ & $\%$ & $\mathrm{n}$ & $\%$ & \\
\hline \multirow[t]{2}{*}{ Doğum şekli } & Normal Doğum & 76 & 49,7 & 77 & 50,3 & \multirow[t]{2}{*}{1,000} \\
\hline & Sezaryen & 24 & 51,1 & 23 & 48,9 & \\
\hline \multirow[t]{9}{*}{ Doğum Komplikasyonu } & Yok & 72 & 50,3 & 71 & 49,7 & 0,276 \\
\hline & Düşük apgar & 9 & 69,2 & 4 & 30,8 & \\
\hline & PROM & 7 & 28 & 15 & 72 & $<0,001$ \\
\hline & IUGR & 2 & 66,7 & 1 & 33,3 & \\
\hline & Mekonyum varlığı & 2 & 100,0 & 0 & 0,0 & \\
\hline & Dekolman plesenta & 0 & 0,0 & 1 & 100,0 & \\
\hline & Oligohidroamnios & 2 & 50,0 & 2 & 50,0 & \\
\hline & Polihidroamnios & 2 & 50,0 & 2 & 50,0 & \\
\hline & Preeklampsi & 2 & 66,7 & 1 & 33,3 & \\
\hline \multirow[t]{2}{*}{ Düşük Öyküsü } & Var & 6 & 37,5 & 10 & 62,5 & 0,435 \\
\hline & Yok & 94 & 51,1 & 90 & 48,9 & 0,101 \\
\hline \multirow[t]{2}{*}{ Kürtaj Öyküsü } & Var & 2 & 20,0 & 8 & 80,0 & \\
\hline & Yok & 98 & 51,6 & 92 & 48,4 & \\
\hline \multirow[t]{2}{*}{ Sigara } & Var & 9 & 20,9 & 34 & 79,1 & $<0,001$ \\
\hline & Yok & 91 & 58,0 & 66 & 42,0 & \\
\hline \multirow[t]{2}{*}{ Alkol } & Var & 1 & 50,0 & 1 & 50,0 & 1,000 \\
\hline & Yok & 99 & 50,0 & 99 & 50,0 & \\
\hline \multirow[t]{2}{*}{ Allerji } & Var & 0 & 0,0 & 0 & 0,0 & - \\
\hline & Yok & 100 & 50,0 & $\begin{array}{c}10 \\
0\end{array}$ & 50,0 & \\
\hline \multirow[t]{2}{*}{ Ek hastalık } & Var & 8 & 50,0 & 8 & 50,0 & 1,000 \\
\hline & Yok & 92 & 50,0 & 92 & 50,0 & \\
\hline \multirow[t]{5}{*}{ Eğitim düzeyi } & İlkokul & 8 & 61,5 & 5 & 38,5 & $\mathbf{0 , 0 2 1}$ \\
\hline & Ortaokul & 4 & 33,3 & 8 & 66,7 & \\
\hline & Lise & 30 & 39,0 & 47 & 61,0 & \\
\hline & Ön lisans & 41 & 65,1 & 22 & 34,9 & \\
\hline & Lisans & 17 & 48,6 & 18 & 51,4 & \\
\hline \multirow[t]{2}{*}{ Sosyal güvencesi } & Sgk & 88 & 50,3 & 87 & 49,7 & 1,000 \\
\hline & Yeşil kart & 12 & 48,0 & 13 & 52,0 & \\
\hline
\end{tabular}

n: Sayı; \%:Yüzde; $\mathrm{P}<0,05$ istatistiksel olarak anlamlı fark mevcut. 